\title{
Noise Generated by Portable Saw in Different Construction Materials
}

\author{
Adriano A. R. Barbosa*, Stelamaris R. Bertoli \\ School of Civil Engineering, University of Campinas, PO Box 6021, Campinas City, São Paulo State 13083-970, Brazil \\ *Corresponding author: adriano@ifsp.edu.br
}

\begin{abstract}
As part of efforts to identify sources of noise pollution from construction, a methodology is developed here for the standardized assessment of noise from masonry saws, which are electric cutters that are commonly used in the industry. Such standardized assessments could aid the development of quieter machines and also of less disruptive and safer industrial practices. The proposed methodology compares the noise generated during cutting with that of free-running non-cutting equipment in accordance with ISO 3744:2010, which specifies methods of determining sound power levels of noise sources via measurement of sound pressure for an essentially free field over a reflecting plane. The cutting of the proposed standard load (concrete slabs) and different building materials was louder than the disengaged saw. The highest observed sound power level was $110.1 \mathrm{~dB}$. The smallest difference observed between the cutting and disengaged saw was $5.5 \mathrm{~dB}$. Noise generated by the saw was quantitatively assessed. The results allowed a standard material to be proposed for use in tests determining the sound power levels of masonry saws. This study also contributes to the analysis of occupational noise generation, considering the difficulties in obtaining previously reported values of the sound spectrum of masonry saws.
\end{abstract}

Keywords: noise - measurement, tools, masonry saw, assessment, building material- standardization

Cite This Article: Adriano A. R. Barbosa, and Stelamaris R. Bertoli, "Noise Generated by Portable Saw in Different Construction Materials.” American Journal of Civil Engineering and Architecture, vol. 5, no. 1 (2017): 17-24. doi: 10.12691/ajcea-5-1-3.

\section{Introduction}

The World Health Organization and the Brazilian Social Security Statistical Yearbook 2010 identify various illnesses associated with the construction industry [1]. Noise from construction is imputed as a contributor to illness and is treated as a public health issue. Research in the United States into the prevention of occupational hearing loss stresses the importance of research and prevention [2]. The health and safety of workers and the quality of life of those near industrial works are being considered increasingly important. Noise has been shown to increase blood pressure, cause stress reactions, and increase the risks of myocardial infarctions and strokes [3]. Construction noise, which is particularly annoying to society, has significant contributions from machines and tools [4]. The World Health Organization [5] recognizes noise pollution as the third most prevalent type of pollution after air and water pollution. The construction industry and its various machines and tools are significant noise makers. The United States Institute for Occupational Safety and Health states that about $90 \%$ of United States building workers are exposed to noise levels greater than $85 \mathrm{~dB}$ (A) [6]. Brazil's construction sector is one of the country's quickly most expanding according to the research institutes and trade unions for civil construction: some industry data suggest that the number of jobs in this sector has doubled in the last decade [7].
Builders seek new processes and materials to reduce the time and labor costs of their work [8]. However, mechanized construction is noisy, with the most powerful equipment often being the loudest [9]. Hand-held electrical equipment is versatile and precise; there is a diverse range of such tools, and they are often inexpensive. They are widely used throughout construction, from infrastructure to finishing and repairs. The masonry saw is a common example. In Brazil, masonry saws are increasingly used for finishing in ceramic plates. The Brazilian Association of Ceramic Tile Manufacturers [10] states that the production and consumption of ceramic coatings in Brazil doubled in the last decade.

A full assessment of the noise conditions in a loud environment requires knowledge of the noise generated by each particular source. Equipment manufacturers usually provide values of the sound pressure levels measured at a set distance from their equipment. The sound pressure level depends on the conditions of the propagating sound, including the presence of obstacles. Various environmental factors can influence the spread of sound, such as temperature, pressure, and relative humidity. Besides the directivity and source position, the material being worked with can also affect the noise associated with certain equipment. The assessment of both ambient noise and noise from specific pieces of equipment at construction sites is important to the development of quieter practices. Masonry saws are louder when cutting materials than when running freely [11]. 
This work proposes a standard material for use with existing standard assessment methods to allow the standardized assessment of the sound power levels of operating masonry saws. Data gathered from such standardized assessments could aid the development of less irritating industrial practices.

\section{Characteristics of Masonry Saws and Diamond Abrasive Blades}

\subsection{Masonry Saws}

Masonry saws cut stone, concrete, masonry, ceramics, and glass. They are hand-held and portable. The average power of the motor is $1,400 \mathrm{~W}$ and the removable diamond disk rotates at approximately 12,000 rpm. They can cut wet or dry, straight or at angles, and are widely used for minor cuts and floor finishing for tiles, bricks, and wood. Such saws are versatile, practical, light, and ergonomic.

\subsection{Diamond Abrasive Blade}

The diamond abrasive blade that is used with a masonry saw is a metal disk. Its cutting area is either continuous or segmented and set with industrial diamond crystals. Blades must comply with the ABNT NBR 15910:2010 set of specifications [12]: 12.000-14.000 rpm rotation; 110-125 mm diameter; $20 \mathrm{~mm}$ central bore; $1.4-1.6 \mathrm{~mm}$ thickness; 6-8 mm diamond height; $1.8-2.2 \mathrm{~mm}$ diamond thickness.

\section{International Standard Sound Power Level Measurement}

The international standard ISO $3744: 2010$ [13] is part of the ISO 3740 series of standards for assessing sound power levels. It specifies methods of measuring sound pressure levels on a surface enveloping the noise source in an environment that approximates an acoustic free field over a reflecting plane. This standard aims to achieve standardized determination of sound power and energy levels from noise sources, such as machinery, equipment, and their sub-assemblies. The specified methodology requires assessment in the open air or a wide environment in which reflected energy does not significantly influence the energy radiated by the source.

\section{Materials and Methods}

This work aims to develop a methodology compatible with the international standard for studying levels of noise generated outdoors by masonry saws, considering the large amounts of dust generated when they cut materials. ISO 3744:2010 states that testing environments should be close to normal operating conditions to ensure the relevance of results. The measurement is conducted as stipulated by the standard; specific cutting conditions (i.e., a standard material to be cut) are proposed to allow the standardized assessment of masonry saws under conditions closely resembling those found during their regular use. To achieve an authentic simulation of regular use, the tests of this work were conducted while trained builders operated the masonry saws.

\subsection{Operations with Masonry Saws}

Masonry saws were used to perform common cutting tasks. The saws and diamond blades were new for the task, in accordance with current standards. The brands and models were readily commercially available and are often used at construction sites. Measurements were performed in an open area of a university campus; the floor was unpaved with some areas of trimmed grass; the surroundings were flat without sources of constructive interference and with low external noise.

\subsection{Reflecting Plane}

ISO 3744:2010 stipulates a reflecting plane to have an absorption coefficient of less than 0.1 for the frequencies of interest. Fibers board with medium density wood MDF (Medium Density Fiberboard) was used here; it was a material with smooth coated high gloss veneer with a thickness of $20 \mathrm{~mm}$. The dimensions of the flat reflector exceeded $0.5 \mathrm{~m}$ on each side of the measurement surface as normative determination The choice of MDF as flat reflector gave up because it is a rigid material and plan with adequate absorption coefficient at the frequencies of interest. The dimensions of the used MDF plane were 3.45 $\times 3.45 \mathrm{~m}$ (area $11.9025 \mathrm{~m}^{2}$; Figure 1 and Figure 2c).

\subsection{Measurements and Materials}

Sound pressure levels of background noise were measured and compared with those of masonry saws running freely and while cutting cement slabs (the proposed standard load), ceramic plates, and slate. To ensure greater reproducibility of the assay, two types of standardized flat concrete slab were prepared based on the characteristics of the materials used in the pre-test. The cement slabs (dimensions $0.40 \times 0.40 \mathrm{~m}$, thickness 2 or $4 \mathrm{~cm}$ ) were fabricated by a technician using a specific composition of mortar made using a 1:2:0.45 volume ratio of portland cement type II (moderate sulfate resistance), aggregate quartz sand with a specific gravity of $2.58 \mathrm{~g} \mathrm{~cm}^{-3}$, and treated water. The ceramic plates (model A5-3011, hue 210, classification/lot B27, dimension 0.31 $\times 0.31 \mathrm{~m}$, thickness $0.75 \mathrm{~cm}$ ) were from a manufacturer that is regularly accredited by the Brazilian Association of Ceramic Tile Manufacturers (ANFACER). They were red flooring tiles from a widely available and popular commercial brand; all the tiles were from the same manufacturing batch. The tiles complied with the international standard for the classification of ceramic tiles (ISO 13006) and also the Brazilian standard for the specification and testing of ceramic tiles (ABNT NBR 13818) [14]. The slate plates (dimension $0.40 \times 0.40 \mathrm{~m}$, thickness $0.70 \mathrm{~cm}$ ) were from the same production lot; they complied with Brazilian standard ABNT NBR 15012:2003 [15]. The slate was of low commercial value; it is regarded as semi-ornamental and is widely used in construction, both commercial and residential. 


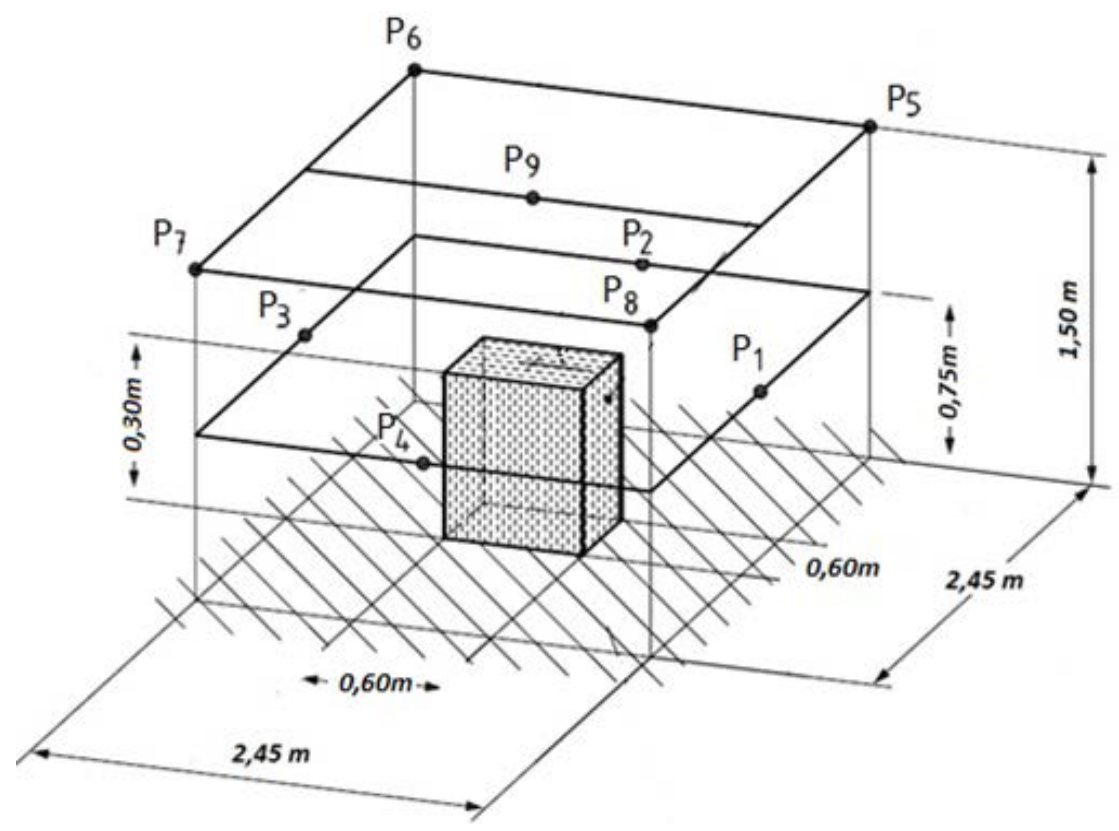

Figure 1. Measurement arrangement

\subsection{Equipment and Measurement Times}

Noise was measured using a sound level meter (Brüel \& Kjær, model 2260). Sound pressure levels were measured with respect to frequency in $1 / 3$ octave bands between 100 and $10.000 \mathrm{~Hz}$. Each measurement was for $10 \mathrm{~s}$, in accordance with ISO 3744:2010.

\subsection{Measurement Arrangement}

According to ISO $3744: 2010$, the condition of the radiation field and the minimum dimensions of the test environment must be arranged such that the measurement points can be described as occupying certain points on the faces of a cuboid-shaped measurement suface. Figure 1 illustrates the measurement points and their physical arrangement.

The hatched area in Figure 1 denotes the plane reflector; the central shaded box represents the noise source located under a reflecting plane. The standard states that six measurements must be performed during each operation of the machine $\left(\mathrm{L}^{\prime} \mathrm{p}_{\mathrm{i}(\mathrm{ST})}\right)$ at each point in the measurement suface.

Figure 2(a) shows the masonry saw used. Figure 2(b) depicts it cutting marble in an open field on a plane reflector. Figure 2(c) shows the projection of the measurements surface.

\subsection{Calculations}

The sound pressure levels from the measurements were determined as follows:

$$
\overline{L_{p(\mathrm{ST})}^{\prime}}=10 \lg \left[\frac{1}{N_{\mathrm{M}}} \sum_{i=1}^{N_{\mathrm{M}}} 10^{0,1} L_{p i(\mathrm{ST})}^{\prime}\right] \mathrm{dB},
$$

where $L_{p(\mathrm{ST})}^{\prime}$ is the mean frequency-band sound pressure level in decibels $(\mathrm{dB})$ measured from the positions in the measurement suface test (ST), and $N_{\mathrm{M}}$ is the number of microphone positions used in the measurement surface.
The mean sound pressure level of the background noise $L_{p(\mathrm{~B})}$ shall be calculated using equation:

$$
\overline{L_{p(\mathrm{~B})}}=10 \lg \left[\frac{1}{N_{\mathrm{M}}} \sum_{i=1}^{N_{\mathrm{M}}} 10^{0,1} L_{p i(\mathrm{~B})}\right] \mathrm{dB},
$$

where $L p_{i}(B)$ is the time-averaged sound pressure level of the background noise measured at the $i$ th microphone position, or ith microphone traverse, in decibels, and $N_{M}$ is the number of microphone positions or individual microphone traverses.

The surface time-averaged sound pressure level, $\overline{L_{p}}$, shall be calculated by correcting the mean time-averaged sound pressure level, $L_{p}^{\prime}(\mathrm{ST})$, for background noise $\left(K_{1}\right)$ and for the influence of the test environment $\left(K_{2}\right)$ using Equation (3):

$$
\overline{L_{p}}=\overline{L_{p(\mathrm{ST})}^{\prime}}-K_{1}-K_{2}
$$

The background noise correction, $K_{1}$, shall be calculated using Equation (4):

$$
K_{1}=-10 \lg \left(1-10^{-0,1 \Delta L_{p}}\right) \mathrm{dB}
$$

where:

$$
\Delta L_{p}=\overline{L_{p(\mathrm{ST})}^{\prime}}-\overline{L_{p(\mathrm{~B})}} .
$$

The weighted average of the sound pressure levels of the measurement suface $\left(L_{p}\right)$ can be used to calculate the sound power $\left(L_{w}\right)$, which considers noise levels generated in the vicinity of the source and their corrections, as follows:

$$
L_{W}=\overline{L_{p}}+10 \lg \frac{S}{S_{0}} \mathrm{~dB},
$$

where $S$ is the area $\left(\mathrm{m}^{2}\right)$ of the measurement surface, and $S_{0}=1 \mathrm{~m}^{2}$. 

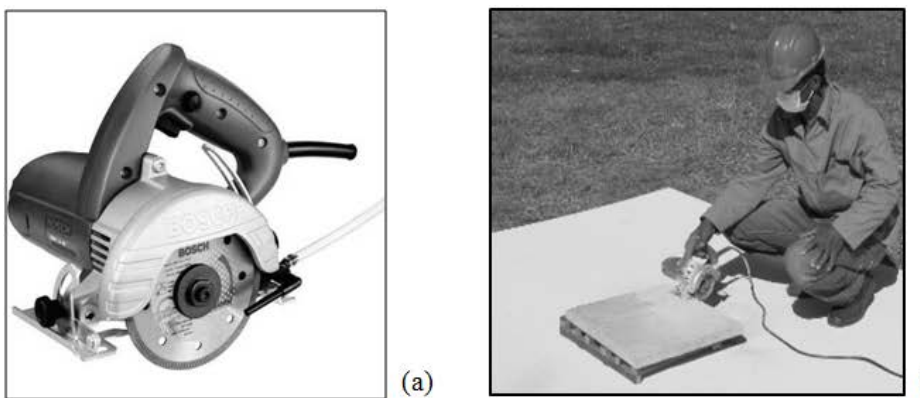

(b)

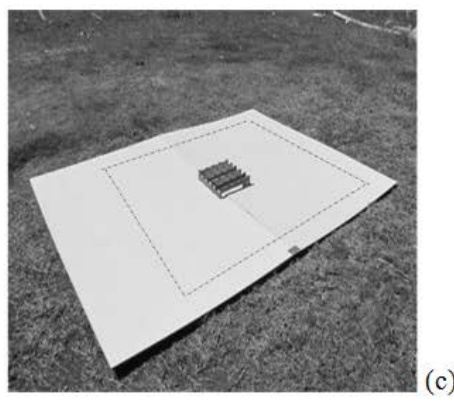

(c)

Figure 2. (a) The tested masonry saw, (b) its use in an open field over a plane and (c) projection of the measurement surface

\section{Results and Discussion}

Measurements were taken under conditions of background noise only, the machine freely running without cutting, and also while cutting the different dry materials. Six $10 \mathrm{~s}$ measurements of the sound pressure level were taken at each of the nine points of reference (P1-P9, Figure 1) as stipulated by ISO 3744:2010. The mean frequency-band or average sound pressure level $\left(\overline{L_{p}}\right)$ of the measurement suface was then calculated for each case. The sound pressure levels measured for the free-running non-cutting saw (Figure 3) and for the saw during the cutting of different materials (Figure 4 Figure 7) were compared against the background noise $\overline{L_{p(B)}}$.

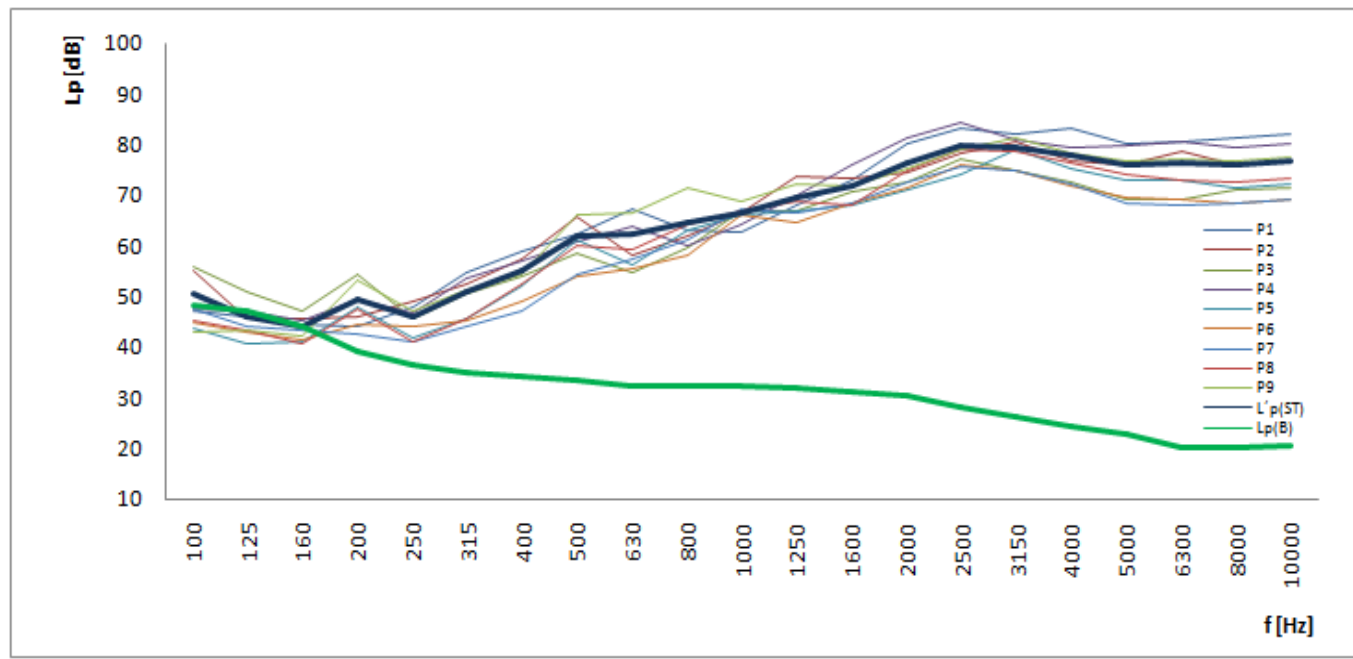

Figure 3. Sound pressure levels of the free-running, non-cutting saw measured at locations P1-P9. Background noise $\overline{L_{p(\mathrm{~B})}}$ and mean frequencyband $\overline{L_{p(\mathrm{ST})}^{\prime}}$ included for reference

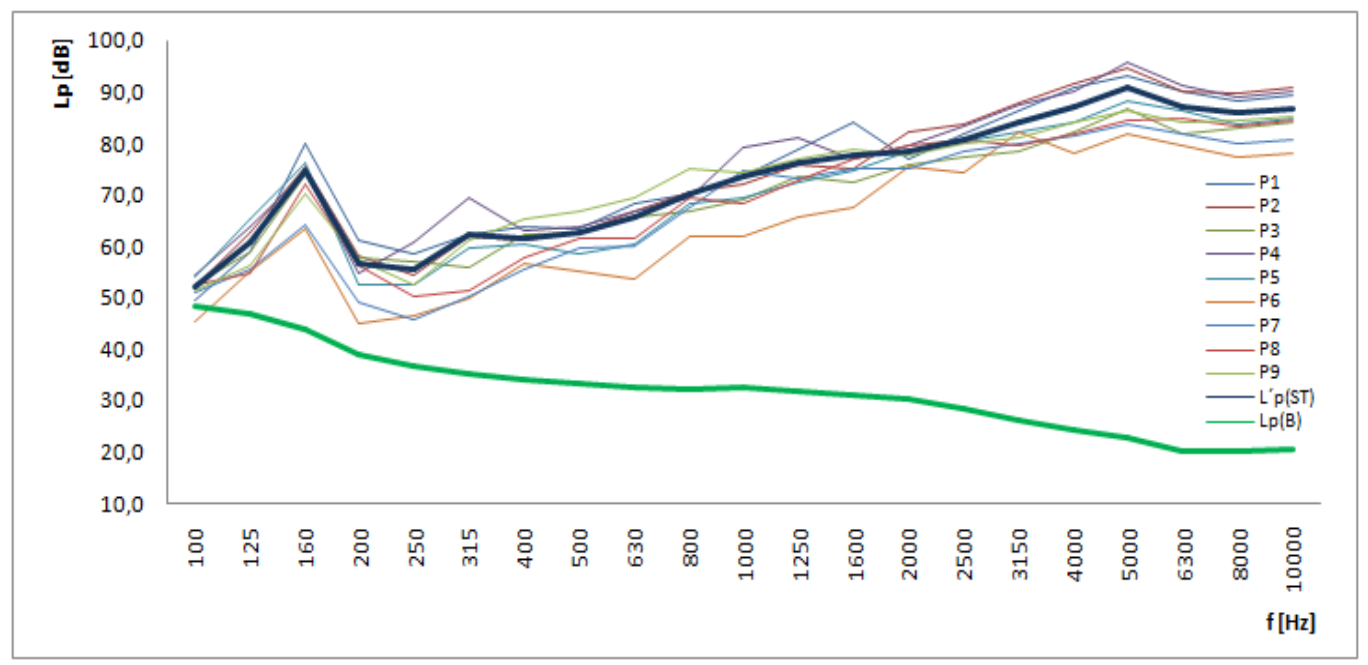

Figure 4. Sound pressure levels during the cutting of ceramic plates measured at locations P1-P9. Background noise $\overline{L_{p(\mathrm{~B})}}$ and mean frequency-band $\overline{L_{p(\mathrm{ST})}^{\prime}}$ included for reference 


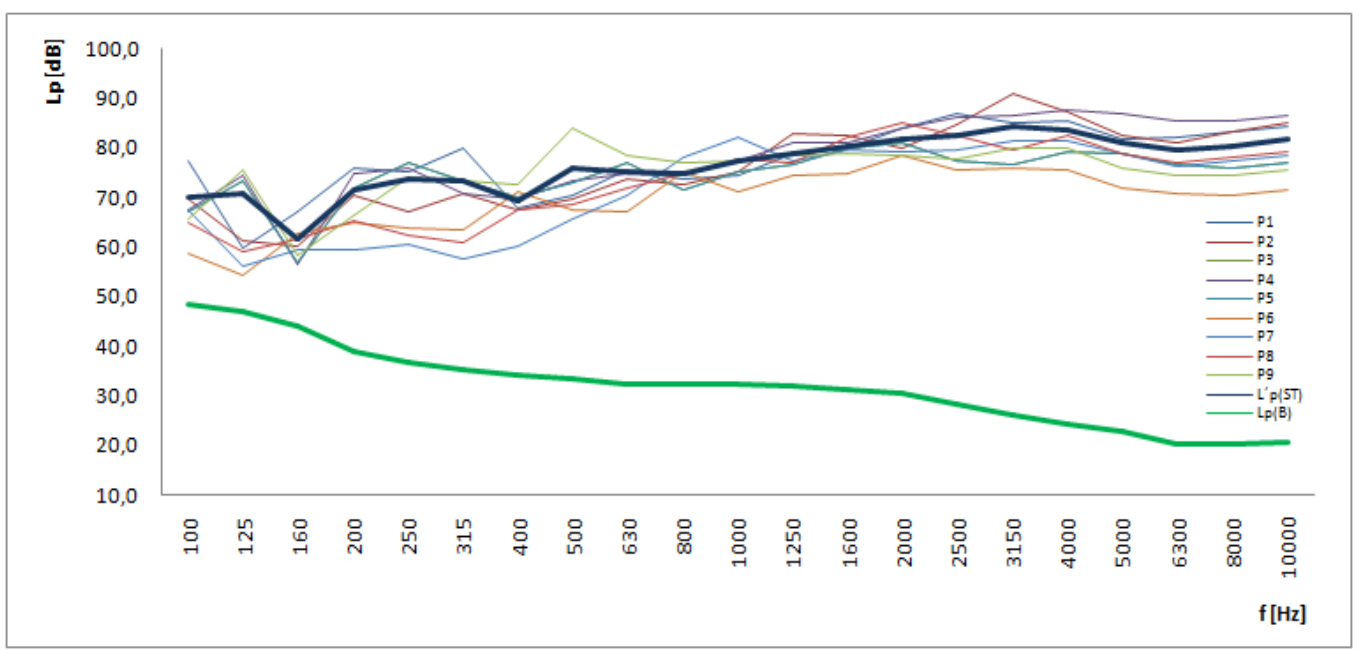

Figure 5. Sound pressure levels during the cutting of the standard concrete slab (2 cm thick) measured at locations P1-P9. Background noise $\overline{L_{p(B}}$ and mean frequency-band $\overline{L_{p(\mathrm{ST})}^{\prime}}$ included for reference

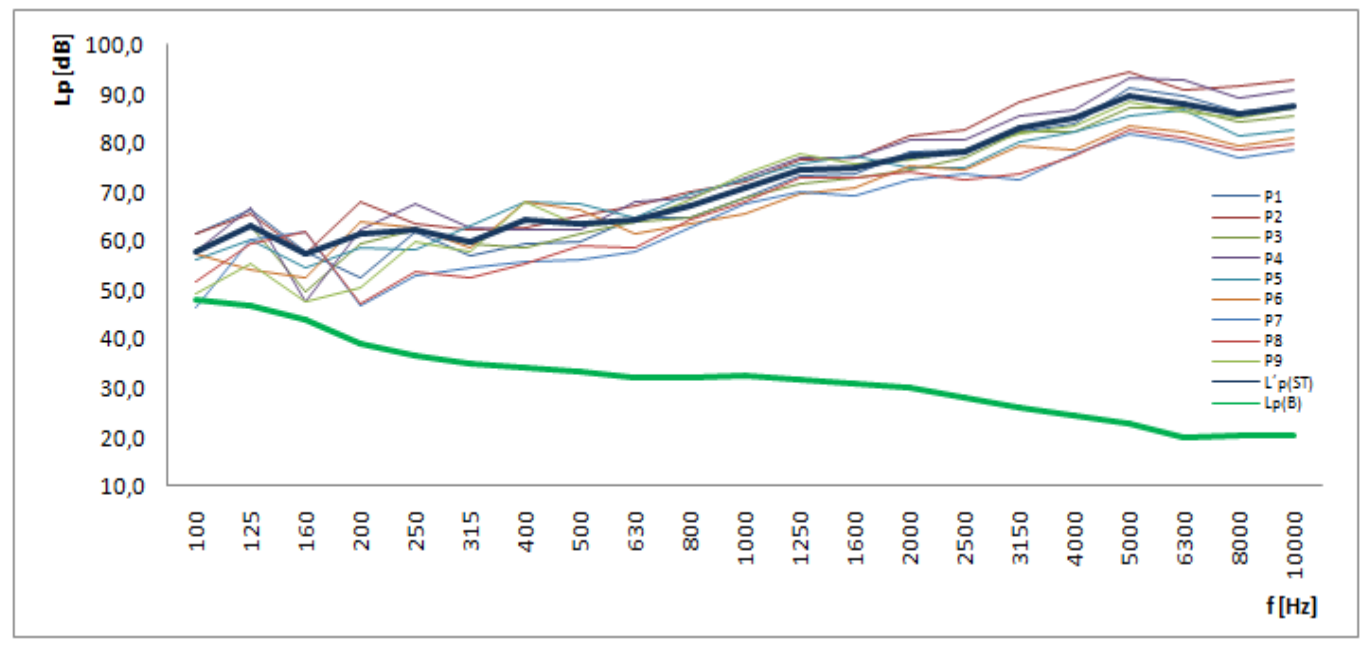

Figure 6. Sound pressure levels during the cutting of the standard concrete slab (4 cm thick) measured at locations P1-P9. Background noise $\overline{L_{p(\mathrm{~B})}}$ and mean frequency-band $\overline{L_{p(\mathrm{ST})}^{\prime}}$ included for reference

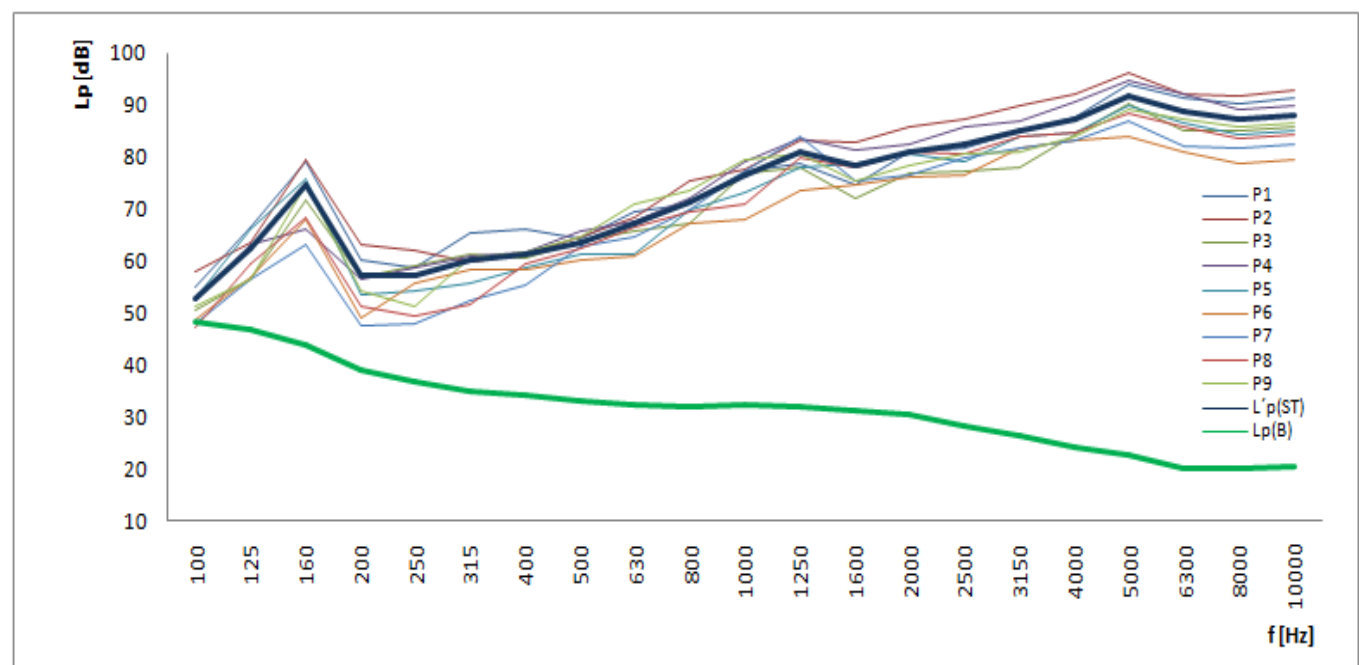

Figure 7. Sound pressure levels during the cutting of slate measured at locations P1-P9. Background noise $\overline{L_{p(\mathrm{~B})}}$ and mean frequency-band $\overline{L_{p(\mathrm{ST})}^{\prime}}$ included for reference 
The noise levels showed fairly uniform increases as frequency increased from 200 to $5000 \mathrm{~Hz}$. At no particular measurement point was the measured noise greatly different from that measured elsewhere; however, the sound pressure levels at some frequencies measured at P2, which is to the left of the operator and the side of the saw motor, were often the greatest. P6, to the rear of the operator, was generally the quietest location. The difference in noise levels relative to the background was less than $10 \mathrm{~dB}$ at frequencies up to $200 \mathrm{~Hz}$ during cutting and up to $315 \mathrm{~Hz}$ during non-cutting.

\subsection{Comparison of Sound Pressure Levels}

Figure 8 shows the average spectrum $\left(L_{p}\right)$ of the sound pressure levels at the different points during the operation of the saw.

Sound pressure was greater during cutting than during the free-running of the non-cutting saw. The sound pressure levels shown during the cutting of the 4-cm-thick standard concrete load follow a similar curve to the cutting of the other ceramic and slate materials.

\subsection{Comparison of Sound Pressure Levels for Different Operators}

A comparison of the noise generated by different masonry saw operators identified the similarity of the sound pressure levels during the cutting operation. However, it is not a criteria that determines the choice of the standard load in this study. In the overall analysis obtained a standard deviation of $1.4 \mathrm{~dB}$ for standard 4-cmthick slab and a standard deviation of $1.0 \mathrm{~dB}$ for standard 2-cm-thick slab.

\subsection{Comparison of Sound Power Levels}

Eq. (2) was used to calculate the sound power levels $\left(L_{w}\right)$ during operation of the saw under normal environmental conditions from the measured sound pressure levels considering the surface area of the measurement surface (Figure 1).

Figure 9 compares the sound power levels measured under different operating conditions at frequency bands of $1 / 3$ octave.

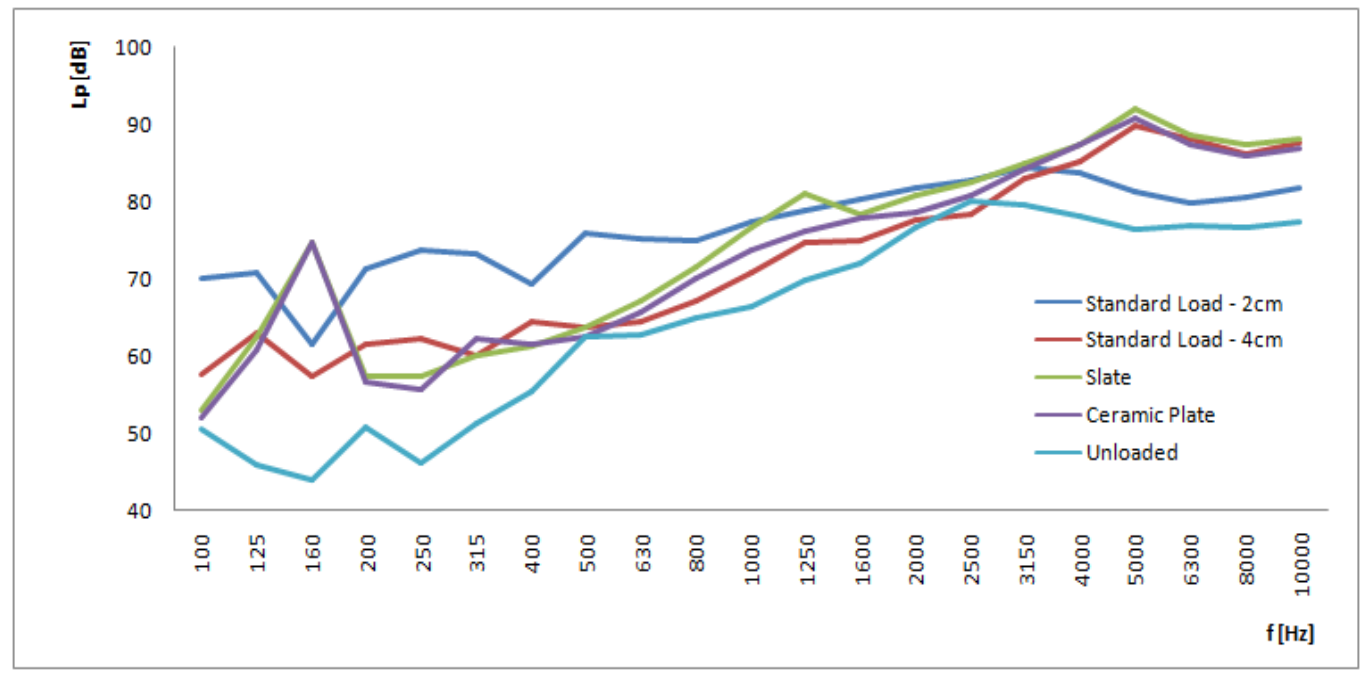

Figure 8. Sound pressure levels during operation of the saw

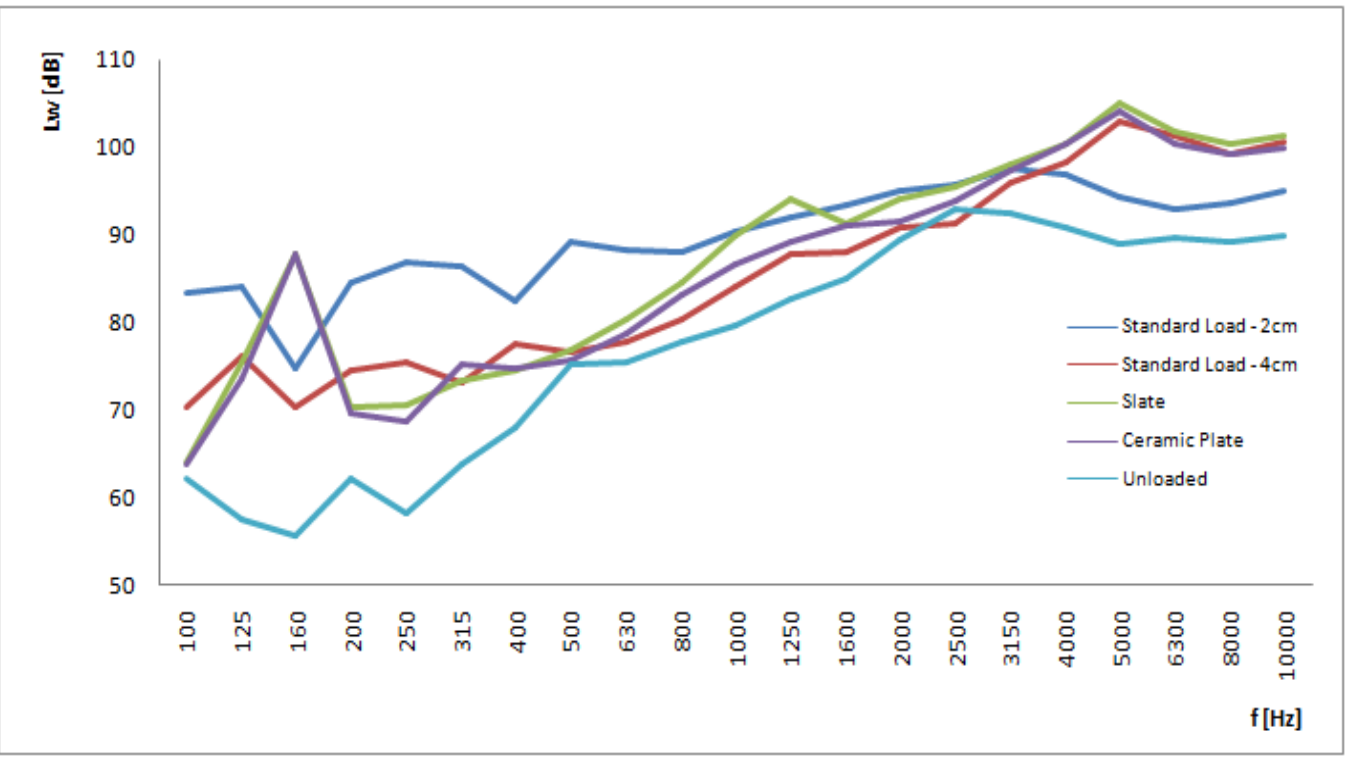

Figure 9. Sound power levels during operation of the saw 
Table 1. Comparison of noise levels generated at points P1-P9, $L_{w}(\mathrm{~dB})$

\begin{tabular}{|c|c|c|c|c|c|c|}
\hline $\mathrm{f}$ & Standard Load - 2cm & Standard Load - 4cm & Slate & Ceramic Plate & Unload & Standard Deviation \\
\hline$(\mathrm{Hz})$ & $\mathrm{Lw}[\mathrm{dB}]$ & $\mathrm{Lw}[\mathrm{dB}]$ & $\mathrm{Lw}[\mathrm{dB}]$ & $\mathrm{Lw}[\mathrm{dB}]$ & $\mathrm{Lw}[\mathrm{dB}]$ & \\
\hline 100 & 83,3 & 70,4 & 64,2 & 63,9 & 62,2 & 8,7 \\
\hline 125 & 84,0 & 76,3 & 75,6 & 73,7 & 57,7 & 9,7 \\
\hline 160 & 74,7 & 70,4 & 88,0 & 87,8 & 55,8 & 13,4 \\
\hline 200 & 84,6 & 74,6 & 70,4 & 69,8 & 62,2 & 8,2 \\
\hline 250 & 86,8 & 75,5 & 70,6 & 68,8 & 58,4 & 10,4 \\
\hline 315 & 86,4 & 73,1 & 73,3 & 75,3 & 64,0 & 8,0 \\
\hline 400 & 82,6 & 77,6 & 74,5 & 74,8 & 68,1 & 5,3 \\
\hline 500 & 89,2 & 76,8 & 76,8 & 75,7 & 75,2 & 5,9 \\
\hline 630 & 88,3 & 77,7 & 80,4 & 78,8 & 75,5 & 4,9 \\
\hline 800 & 88,1 & 80,3 & 84,6 & 83,2 & 77,7 & 4,0 \\
\hline 1250 & 92,0 & 87,9 & 94,1 & 89,4 & 82,7 & 4,4 \\
\hline 1600 & 93,4 & 88,1 & 91,4 & 91,0 & 84,9 & 3,3 \\
\hline 2000 & 95,0 & 90,8 & 94,1 & 91,7 & 89,5 & 2,3 \\
\hline 2500 & 95,8 & 91,4 & 95,6 & 94,0 & 92,9 & 1,8 \\
\hline 3150 & 97,6 & 96,1 & 98,1 & 97,3 & 92,5 & 2,3 \\
\hline 4000 & 96,9 & 98,3 & 100,5 & 100,4 & 90,9 & 4,0 \\
\hline 5000 & 94,3 & 103,0 & 105,0 & 104,1 & 89,1 & 7,0 \\
\hline 6300 & 92,9 & 101,3 & 101,8 & 100,4 & 89,6 & 5,6 \\
\hline 8000 & 93,6 & 99,2 & 100,4 & 99,2 & 89,3 & 4,8 \\
\hline 10000 & 95,0 & 100,7 & 101,3 & 100,0 & 90,0 & 4,8 \\
\hline Lw - Linear [dB] & 105,6 & 108,4 & 110,1 & 109,0 & 100,1 & 4,0 \\
\hline Lw Global [dB(A)] & 105,9 & 108,3 & 110,2 & 109,1 & 100,6 & 3,8 \\
\hline
\end{tabular}

The mean sound power level generated at points P1-P9, the overall sound pressure level $\left(L_{w}\right)$ are listed in Table 1.

\subsection{Analysis of the Measurement Uncertainty}

The amount of deviation to be considered for the uncertainty analysis of sound power $\left(\mathrm{L}_{\mathrm{w}}\right)$, obtained from the indices of stable operating conditions and assembly tests in outdoor areas with intermediate-level accuracy in Grade 2, according with ISO 3744:2010, in frequencies from 100 to $10,000 \mathrm{~Hz}$ is $\mathrm{U}=4.3 \mathrm{~dB}$. It is observed that the values of the standard deviation obtained for the overall sound power levels of standard 4-cm-thick slab $(\sigma=0.9 \mathrm{~dB})$ and standard 2-cm-thick slab $(\sigma=2.3 \mathrm{~dB})$, are within the margin of measurement uncertainty considered in this study.

\section{Conclusions}

The noise generated by a masonry saw during cutting of cement slabs (the proposed standard test material) and other building materials was measured and compared with the background noise. The large amount of dust generated during cutting with the saw meant that the method used in an open space on a planar reflector was most suitable. Noise measured during cutting was also compared with the noise of the equipment running while not cutting. The measurement setup (i.e., the positioning of the source and measurement locations) complied with ISO 3744:2010 and was adapted for the specific assessment of the masonry saw, its conditions of loading, and operation. Higher sound pressures were recorded during the cutting of the different materials than during the free running of the non-cutting saw. Average sound pressure levels were calculated by correcting for the sound pressure level at each measurement point, the background noise, and environmental factors.

The taking of measurements at different positions around the saw allowed assessment of whether the presence of the operator interfered with the noise propagation. The noise levels were unstable and inaccurate at lower frequencies; they were higher at higher frequencies, but became more level in the range $1-4 \mathrm{kHz}$. The overall sound pressure and power levels measured during the cutting of the proposed standard materials were close to those generated during the cutting of the other materials (ceramic and slate), suggesting that the adoption of a standard material would allow greater reproducibility of testing results while still generating noise representative of that experienced during regular use of the saw.

From the analysis of measurement uncertainty in the results of sound power levels, according to ISO 3744:2010, it is observed that the proposed cement slabs meet the criteria of the expanded measurement uncertainty and deviations from global levels.

The present results suggest that the most suitable material to be used as a standard for assessing the sound power of masonry saws is the standard 4-cm-thick $40 \times$ $40 \mathrm{~cm}$ concrete slab. 
The sound levels generated during the cutting of this proposed standard material are representative; they are similar to those generated during the cutting of ceramic tiles and slate, which are commonly used building materials that are often cut by masonry saw.

As proposals for future work, it is suggested: Relating the physical characteristics of the materials with the cutting noise generated; Propose an automated device to replace the operator with the particular sensitivity and handling of the saw; Study of the vibration behavior of plates, resonance frequencies, harmonics series generated and its interference with the generated noise; Investigation of sound power by acoustic intensimetry; Study with machines and different types of diamond blades and its relations with the noise generated.

Overall, this study contributes to the analysis of noise generated by masonry saws on construction sites, for the purposes of occupational and environmental comfort.

\section{References}

[1] BRAZILIAN ASSOCIATION OF TECHNICAL STANDARDS ABNT NBR 13818:1997 - Ceramic plates for coating: Specification and test methods. 78p, 1997.

[2] STEPHENSON, M. R. National Research Agenda for the Prevention of Occupational Hearing Loss. Semin Hear Journal. Thieme Medical Publishers, New York, 2013.

[3] SJÖSTRÖM, M.; LEWNÉ, M.; ALDERLING, M.; WILLIX, P.; BERG, P.; GUSTAVSSON, P.; A Job-Exposure Matrix for Occupational Noise: Development and Validation. Annals of Occupational Hygiene, Disponível em:

http://annhyg.oxfordjournals.org/content/early/2013/02/01/annhyg .met001.full.pdf , 2013.

[4] BALLESTEROS, M. J.; FERNÁNDEZ, M. D.; QUINTANA S.; BALLESTEROS, J. A.; GONZÁLEZ I. Noise emission evolution on construction sites. Measurement for controlling and assessing its impact on the people and on the environment. Building and
Environment Journal, Volume 45, Issue 3, March 2010, Pages 711-717.

[5] WORLD HEALTH ORGANIZATION (WHO). Resumé d'Orientation des directives de ROMS Relatives au Bruit dans l'Environmental. Disponível em: http://www.who.int, 2011.

[6] NIOSH - National Institute for Occupational Safety and Health. Occupational noise exposure - revised criteria 2011. Ohio: U.S. Department of Health and Human Services. Available at: http://www.cdc.gov/niosh. Accessed on 17 Out, 2013.

[7] SINDUSCON / FGV PROJECTS. 55 ${ }^{\text {th }}$ National Survey of Construction Industry. Available in

http://www.sindusconsp.com.br. Accessed on 29/09/2013 at 23h21min, São Paulo, Junho, 2013.

[8] OLIVEIRA, J. P. B. Optimization of constructive processes through the integration of technology in the construction industry. ROCA Repository - Federal Technological University of Parana. Curitiba, Brazil, 2013.

[9] SEIXAS, N. S.; NEITZEL, R.; STOVER, B.; SHEPPARD, L.; FEENEY, P.; MILLS, D.; KUJAWA, S. 10-Year prospective study of noise exposure and hearing damage among construction workers. Occupational \& Environmental Medicine Journal; Volume 69:643-650, Seattle, 2012.

[10] ANFACER (BRAZILIAN ASSOCIATION OF CERAMIC MANUFACTURERS). Industry figures. São Paulo. Available at http://www.anfacer.com.br. Accessed on December 26, 2011.

[11] BARBOSA, A. A. R.; BERTOLI, S. R. Noise generated by portable masonry saws operating materials in constructions. $41^{\text {st }}$. International Congress and Exposition on Noise Control Engineering - INTERNOISE, New York, August 19-22, 2012.

[12] BRAZILIAN ASSOCIATION OF TECHNICAL STANDARDS ABNT NBR 15910:2010 - Tools portable electric motor operated Safety: Particular requirements for masonry saw. 15p, 2010.

[13] INTERNATIONAL ORGANIZATION FOR STANDARDIZATION. ISO 3744 - Acoustics - Determination of sound power levels of noise sources using sound pressure: Engineering methods for an essentially free field over a reflecting plane. Switzerland, 2010.

[14] BRAZILIAN ASSOCIATION OF TECHNICAL STANDARDS ABNT NBR 15012: 2003 - Rocks coatings for buildings. 10p, 2003.

[15] BRAZILIAN ASSOCIATION OF TECHNICAL STANDARDS ABNT NBR 13818: 1997 - Ceramic plates for coating: Specification and test methods. 78p, 1997. 